\title{
Study on Consumer Behaviour and Food Safety of Organic Products in Pakistan
}

\author{
Waqas, Aslam ${ }^{*}$, Chen Hong ${ }^{2}$ \\ ${ }^{1}$ School of Economics and Management, Northeast Forestry, University, 150040, Harbin, P.R. China \\ ${ }^{2} \mathrm{PhD}$ Supervisor, School of Economics and Management, Northeast Forestry, University, 150040, Harbin, P.R. China
}

\begin{abstract}
Alongside the advancement in economic activities, it is seen that customer enthusiasm for organic products has expanded. Together with long lasting of life and wanting to build the personal satisfaction are of incredible significance in this expansion. The connection between studied variables and demographic factors were likewise examined by methods for Chi-square analysis. The study was conducted on 155 participants selected by utilizing convenience testing technique. Findings revealed that organic food attitude and safety of food were observed to be significant for intentions to purchase organic food. Then again, the results revealed that health consciousness was found insignificance for purchasing intentions of organic food. As for statistic qualities, profession and purchasing attitudes towards organic edibles items were observed to be interlinked with one another. It was likewise discovered that gender discrimination had an impact on organic edibles intentions.
\end{abstract}

\section{Introduction}

With the advancement in food production techniques, significant increase in the production of foodstuffs and diversification has emerged. However, the widespread use of these substances has triggered more emergence of various diseases that may also affect cancer, obesity and genetics. The concerns that occur in consumers ' minds have begun to differentiate their food consumption preferences.

Nowadays, many non-organic inputs and methods used to increase the efficiency are obtained. In recent years, with objections from different circles, the products obtained by the Convention have begun to emphasize a number of adverse effects on human health and the environment. In food production, the inputs affecting human health;

A) In seed stage: genetically modified seeds. B) During the cultivation process: industrial solvent and chemical food additives, pest medications, other synthetic pesticide chemicals and chemicals fertilizers. C) Post Harvest: irradiation i.e. to maintain the quality of the product, to increase shelf life and to provide hygiene X, gamma and UV rays are possible to sort.

Increasing health and environmental concerns in the above affect the demand for organic foods has getting fame day by day (Ronald et. al 2018.). Consumer-oriented concerns are affecting businesses today, especially in the name of creating sustainable ecosystems and consumer welfare as a requirement of devalue the marketing. Organic food production is a human and environmentally oriented production concept based on the preservation and improvements of ecological diversity by using as few agricultural inputs as possible. Consumer and environmental oriented approaches are consuming consumers to consume more organic food, while producers produce more organic foods.

Pakistan is continuous with the agricultural reform in traditional way, the division of land, industrial agriculture as the most important obstacle in the development of agriculture. Organic food production in Pakistan started from 2010 by the keen struggle of NARC and Lok Sajh NGO (Husnain et. al 2017).

Organic food consumption in advanced economies in the world has increased rapidly in recent years and has the also more effective for consumers regarding its environmental awareness (Srinieng and Thapa. 2018).

However, a different study found that consumers are buying organic food not because of the behavior of basic environmental awareness that has revealed health concern (Carfora, V., et al. 2017).

\section{Conceptual framework}

Attitudes towards organic food, organic food, food safety and health awareness, purchase intent are the variables related to the studies below.

\subsection{Attitude towards the Organic food}

In studies conducted, the effect of variables such as gender, age and income status on demographic factors affecting organic food preferences of consumers were examined. According to this, Old wealthy people prefer organic food because they are more conscious about their health, while young consumer use organic food because they are fully aware about its environmental worth. It is observed that 
families with women and children are more conscious about usage of organic products. In addition, a linear relationship was found between the age of the consumer and the preference of organic products and their buying behavior (Davies, Titterington and Cochrane, 1995).

The attitude towards organic foods is related to the intention to purchase and demographic variables (gender, age and occupation). The following hypotheses were developed to investigate whether similar results would be obtained in this study.

$\mathrm{H}_{1}$ : The attitude towards organic foods is effective on the intention to purchase organic food.

$\mathrm{H}_{1} \mathrm{a}$ : There is a relationship between gender and attitude towards organic foods.

$\mathrm{H}_{1}$ b: There is a relationship between age and attitude towards organic foods.

$\mathrm{H}_{1} \mathrm{c}$ : There is a relationship between profession and attitude towards organic foods.

\subsection{Health awareness}

Health awareness requires monitoring of health-related developments and proactive responsibility. Consumers with a high health awareness are more sensitive to environmental protection. These consumers aim to reduce the risk of illnesses that can be caused by taking preventive measures as they motivate themselves to stay healthy and to improve and / or sustain their quality of life. Nowadays, the concept of ap being healthy ap underlined with the slogan (Return to Nature ü is now turned into a life style (Suprapto and Wijaya, 2012: 173). Retailers who emphasize health awareness and quality can easily attract health-conscious consumers to organic products.

Because organic food consumers are a group aware of health awareness, they want to buy and buy healthy and natural foods (Schifferstein and Oude Ophuis, 1998). It is argued that the main factor driving consumers to buy organic food is health awareness (Grankvist and Biel, 2001; Lockie, Lyons, Lawrence and Mummery, 2002). Chen (2009) found that health and environmental care as a result of his research is an important factor in the consumption of organic food, in addition to that, healthy lifestyle has a mediating effect on the positive relationship between health awareness, environmental attitude and consumer's attitude to organic food.

However, the relationship between health awareness and attitude towards organic foods is not fully supported in all studies (Tarkiainen \& Sundqvist, 2005). In some studies, it is controversial whether organic and conventional products are better and better taste (Fillion and Land, 2002; Dangour, Dodhia, Hayter, Allen.

The following hypotheses were developed based on the findings of the study on health awareness, purchasing intention and demographic variables (gender, age and occupation) for organic foods.

$\mathrm{H}_{2}$ : Health awareness has an impact on the intention to purchase organic food.

$\mathrm{H}_{2} \mathrm{a}$ : There is a relationship between gender and health awareness.

$\mathrm{H}_{2} \mathrm{~b}$ : There is a relationship between age and health awareness.
$\mathrm{H}_{2} \mathrm{c}$ : There is a relationship between job and health awareness.

\subsection{Food safety}

Consumers buying organic products are more proactive to their physical risks of food consumption. Organic food means that it does not contain any residues or does not contain any non-organic components.

Most consumers think that food residues cause cancer (Gold, Slone, Ames and Manley, 2001: 799). The traceability of all stages of the supply chain in ensuring the safety of organic food is an important consideration. Due to the increasing sensitivities related to organic foods, each stage in food chain from production to consumption should be controlled by alphanumeric code, barcode etc.

According to the studies on food safety for organic foods, the following hypotheses have been developed.

$\mathrm{H}_{3}$ : Food safety has an impact on the intention to purchase organic food.

$\mathrm{H}_{3} \mathrm{a}$ : There is a relationship between gender and food safety.

$\mathrm{H}_{3}$ b: There is a relationship between age and food safety.

$\mathrm{H}_{3} \mathrm{c}$ : There is a relationship between profession and food safety.

\subsection{Purchase intention for organic products}

Positive developments such as increase in living standards in the lives of consumers, increase in education levels, easier access to information, and social and environmental awareness that are becoming more fashionable increase the awareness of the organic concept which has become a fashion and increase the consumer interest and the intention of purchasing.

Organic food purchase intent, health awareness and perceived value has a positive impact; food safety and religious factors are reported to have a lower impact on consumer buying intent (Shaharudin, Pani, Mansor and Elias, 2010). A linear relationship between healthy perception of organic foods and intention to purchase is mentioned, and although satisfaction with food differs in terms of different variables, it is stated that overall satisfaction with organic foods is higher (Paul and Rana, 2012).

The following H4 hypotheses were developed in relation to the purchase intention for organic foods.

$\mathrm{H}_{4} \mathrm{a}$ : There is a relationship between gender and intention to purchase.

$\mathrm{H}_{4}$ b: There is a relationship between age and purchase intention.

$\mathrm{H}_{4} \mathrm{c}$ : There is a relationship between the profession and the intention to purchase.

The conceptual framework, the attitude towards organic food, health awareness, and the claims that food security has an impact on the purchasing intent were tested separately. In this part of the study, the model given in Figure 1 below is established to test the effect of three variables together on purchase intention. 


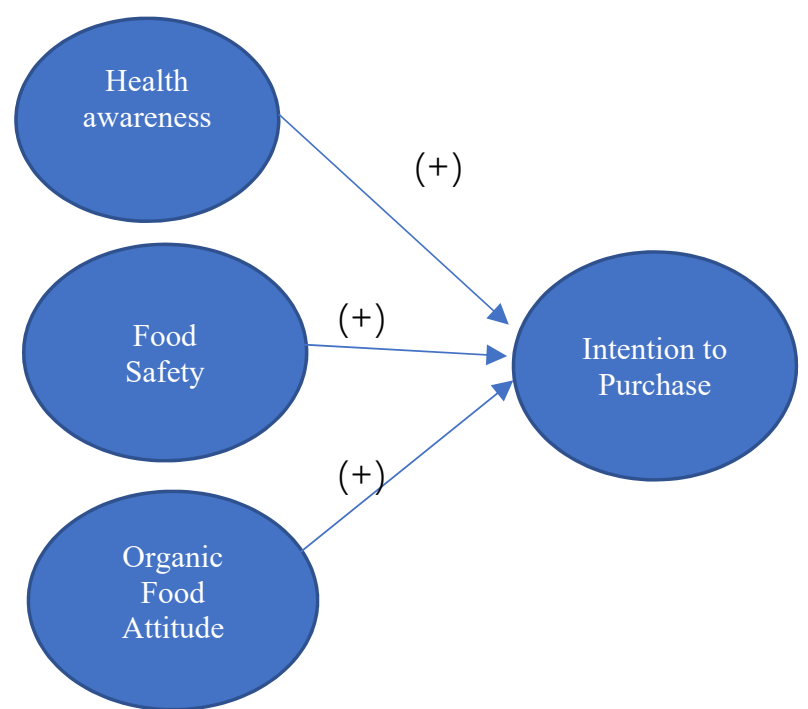

Fig 1. Research Model

\section{Methodology}

The research was carried out on 155 individuals selected from the Faculty of Economics and Administrative Sciences of the two universities in the Eastern Black Sea region, and the subcontractors working at the university cafeterias and security units of the university. The research was carried out using face to face survey method.

In the study, the scales used in the previous researches were used in the measurement of the variables. Gould (1988) for the measurement of health awareness in this context; For measuring food safety, Roddy, Cowan and Hutchinson (1996), and the measures developed by Putrevu and Lord (1994) for the measurement of organic food intention were used. The attitude towards organic foods was measured by taking into account the general attitude statements and the study of Fishbein and Ajzen (1974).

Likert scale was applied as considered $1=$ strongly disagree and totally agree is encoded in 7 .

\section{Data Analysis}

factor analysis was applied showed that variables measuring different phenomena were collected under the same structure in given hypothesis. Correlation between variables was tested for factor analysis. Factor analysis revealed that the scales measuring different structure were at the same size and had high factor loads. The reliability coefficients and the explained variance quantities are given in Table 1 below.

Analysis Results

\begin{tabular}{|c|c|c|c|c|}
\hline \multirow[t]{2}{*}{ Factors and Expressions } & \multicolumn{4}{|c|}{ Factor Loads } \\
\hline & F1 & $\mathbf{F 2}$ & $\mathbf{F 3}$ & F4 \\
\hline \multicolumn{5}{|l|}{ Health Awareness $\alpha=0,860$} \\
\hline $\begin{array}{l}\text { I can physically reflect the state of health very well from } \\
\text { the outside }\end{array}$ & 0,569 & & & \\
\hline I'm very conscious about my health & 0,815 & & & \\
\hline I pay attention to the changes in my health & 0,837 & & & \\
\hline I am often aware of my health & 0,778 & & & \\
\hline I take responsibility for my health & 0,849 & & & \\
\hline As the days go by, I'm aware of my health. & 0,608 & & & \\
\hline \multicolumn{5}{|l|}{ Food Safety $\alpha=0,612$} \\
\hline $\begin{array}{l}\text { Nowadays it contains many food, chemical poison and } \\
\text { fertilizer remains }\end{array}$ & & 0,633 & & \\
\hline $\begin{array}{l}\text { I am very interested in artificial additives and } \\
\text { preservatives found in foods }\end{array}$ & & 0,673 & & \\
\hline
\end{tabular}




\begin{tabular}{|c|c|c|c|c|}
\hline $\begin{array}{l}\text { The quality and reliability of food is of great interest to } \\
\text { me }\end{array}$ & & 0,704 & & \\
\hline \multicolumn{5}{|l|}{ Attitude towards Organic Foods $\alpha=0,926$} \\
\hline Organic foods are more fresh & & & 0,766 & \\
\hline Organic foods are my favorite & & & 0,700 & \\
\hline Organic foods are of superior quality & & & 0,881 & \\
\hline Organic food are natural food products & & & 0,803 & \\
\hline I have positive thoughts about organic foods & & & 0,843 & \\
\hline Organic food products are more delicious & & & 0,816 & \\
\hline $\begin{array}{l}\text { Organic food has more nutritional value than } \\
\text { conventional food }\end{array}$ & & & 0,819 & \\
\hline \multicolumn{5}{|l|}{ Purchase intention $\alpha=0,860$} \\
\hline You can probably buy organic food & & & & 0,874 \\
\hline $\begin{array}{c}\text { I'm probably going to buy organic food in my next water } \\
\text { shopping. }\end{array}$ & & & & 0,822 \\
\hline I will definitely try the organic food in the near future & & & & 0,771 \\
\hline Variance $(\%)$ & 15,62 & 6,68 & 36,07 & $\mathbf{9 , 0 1}$ \\
\hline Total Explanation (\%) & & 67,38 & & \\
\hline
\end{tabular}

Table 2. Descriptive Statistics and Correlation Coefficients of Variables

\begin{tabular}{|c|c|c|c|c|c|c|c|}
\hline & $\overline{\mathbf{x}}$ & $\mathbf{s S}$ & S. E & HA & FS & OFA & PI \\
\hline $\begin{array}{c}\text { Health Awareness } \\
\text { (HA) }\end{array}$ & 5,25 & 1,17 & 0,09 & --- & & & \\
\hline Food Safety (FS) & 5,44 & 1,02 & 0,08 & $0,32 * *$ & ---- & & $-0,23^{* *}$ \\
\hline $\begin{array}{c}\text { Organic Food } \\
\text { Attitude (OFA) }\end{array}$ & 5,99 & 1,13 & 0,09 & $0,32^{* *}$ & -- & \\
\hline $\begin{array}{c}\text { Purchase Intent } \\
\text { (PI) }\end{array}$ & 4,75 & 1,62 & 0,13 & $0,24 * *$ & $0,28^{* *}$ & $0,50^{* *}$ & - \\
\hline
\end{tabular}

${ }^{*} p<0,05 .{ }^{* *} p<0,01$ (two tailed)

Accordingly, the estimated model is as follows:

Intention to purchase $=-0,8506+0,064$ (Health Awareness) + 0,256 (Food Safety) + 0,646 (Attitude to organic foods). Table 3 shows the coefficients of regression analysis. The significance of the coefficients in the model has been tested and on the intention to purchase organic food: food safety $\left(\mathrm{t}_{\mathrm{n}-2 ; \alpha}=2,186 ; \rho<0,05\right)$ and attitude to organic foods $\left(\mathrm{t}_{\mathrm{n}-2 ; \alpha}=6,145 ; \rho<0,01\right)$ coefficients were found to be statistically significant. The effect of health awareness on organic intention to purchase was not significant $\left(t_{n-2 ; \alpha}=0,615 ; \rho=0,54\right)$.

Table 3. Description of Significance

\begin{tabular}{|c|c|c|c|c|}
\hline \multirow{2}{*}{ Variables } & \multicolumn{3}{|c|}{ Purchase intent } \\
\cline { 2 - 5 } & $\boldsymbol{\beta}$ & STD error & $\boldsymbol{t}$ & Sig. \\
\hline The regression constant & $-0,850$ & 0,791 & $-1,075$ & 0,284 \\
\hline Health awareness & 0,064 & 0,104 & 0,615 & 0,540 \\
\hline Food safety & 0,256 & 0,117 & 2,186 & $0,030^{*}$ \\
\hline
\end{tabular}




\begin{tabular}{|c|c|c|c|c|}
\hline Attitude & 0,646 & 0,105 & 6,145 & $0,000 * *$ \\
\hline
\end{tabular}

Dependent variable: Intention to purchase

${ }^{*} p<0,05$. ${ }^{* *} p<0,01$

$R^{2}=0,285 ;$ Durbin-Watson 2,206; $F_{(3,151 ; 0,05)}=20,07 ; \rho<0,001$

Table 4. Descriptive Findings

\begin{tabular}{|c|c|c|c|c|c|c|c|c|}
\hline \multicolumn{2}{|c|}{ Gender } & \multicolumn{2}{c|}{ Profession } & \multicolumn{3}{c|}{ Age } \\
\hline & $f$ & $\%$ & & $f$ & $\%$ & & $f$ & $\%$ \\
\hline Male & 66 & 42,6 & Government & 38 & 24,5 & $17-22$ & 68 & 43,9 \\
\hline Female & 89 & 57,4 & STUDENT & 106 & 68,4 & $22-30$ & 60 & 38,7 \\
\hline & & & PRIVATE & 11 & 7,1 & $30-50$ & 27 & 17,4 \\
\hline Total & 155 & 100,0 & & 155 & 100,0 & & 155 & 100,0 \\
\hline
\end{tabular}

Table 5. Descriptive Statistics of Variables

\begin{tabular}{|c|c|c|c|c|}
\hline & Health awareness & Food safety & $\begin{array}{c}\text { Organic Food } \\
\text { Attitude }\end{array}$ & Purchase intention \\
\hline Average & 5,2559 & 5,4473 & 5,9926 & 4,7570 \\
\hline Median & 5,3333 & 5,6667 & 6,2857 & 5,0000 \\
\hline \multirow{2}{*}{ percentile } & 5,0000 & 5,0000 & 5,8571 & 4,3333 \\
\cline { 2 - 5 } & 6,0000 & 6,0000 & 6,7143 & 5,6667 \\
\hline
\end{tabular}

According to the chi-square test, a statistically significant relationship was found between the intention to purchase only for organic food and gender.

$\chi^{2}(2, N=140)=7,328 ; p<0,05$ Cramer's V =0,229; $p<0,05$.

Table 6. Relationship Between Intention to Purchase and Gender

\begin{tabular}{|c|c|c|c|c|c|}
\hline \multirow{2}{*}{ Gender } & \multicolumn{5}{|c|}{ Purchase Intention } \\
\cline { 2 - 6 } & Low & medium & high & $\chi \mathbf{2}$ & Cramer's V \\
\hline Male & 29 & 16 & 15 & $7,328^{*}$ & 0,229 \\
\hline Female & 21 & 29 & 30 & & \\
\hline$*_{p<0,05}$ & & &
\end{tabular}

Table 7. Relationship between Attitude towards Organic Food and profession

\begin{tabular}{|c|c|c|c|c|c|}
\hline \multicolumn{7}{|c|}{ Purchase intention } \\
\hline Profession & Low & medium & high & $\chi \mathbf{2}$ & Cramer's V \\
\hline Public Official & 7 & 9 & 22 & $19,79^{*}$ & 0,253 \\
\hline Student & 6 & 18 & 82 & & \\
\hline Private Sector Employees & 0 & 7 & 4 & & \\
\hline$p<0,01$ & &
\end{tabular}

Table 8 is the health awareness of demographic factors related to organic food, food safety, attitudes and intention to purchase variables. As seen in the table, it is seen that only two hypotheses (H1c and $\mathrm{H} 4 \mathrm{a}$ ) are accepted and the remaining hypotheses are rejected. 
Table 8. The Results of Hypothesis Related to Demographic Factors

\begin{tabular}{|c|c|c|c|}
\hline Hypothesis & $\chi^{2}$ & $\mathbf{p}$ & Results \\
\hline $\begin{array}{c}\text { H1a There is a relationship between gender and attitude } \\
\text { towards organic foods }\end{array}$ & 0,138 & 0,933 & Rejected \\
\hline $\begin{array}{c}\text { H1b There is a relationship between age and attitude } \\
\text { towards organic foods }\end{array}$ & 4,735 & 0,316 & Rejected \\
\hline $\begin{array}{c}\text { H1c There is a relationship between profession and } \\
\text { attitude towards organic foods }\end{array}$ & 19,790 & $<0,01$ & Accepted \\
\hline $\begin{array}{l}\mathrm{H} 2 \mathrm{a} \text { There is a relationship between gender and health } \\
\text { awareness }\end{array}$ & 2,687 & 0,261 & Rejected \\
\hline $\begin{array}{l}\mathrm{H} 2 \mathrm{~b} \text { There is a relationship between age and health } \\
\text { awareness }\end{array}$ & 5,981 & 0,201 & Rejected \\
\hline $\begin{array}{l}\mathrm{H} 2 \mathrm{c} \text { There is a relationship between the profession and } \\
\text { health awareness }\end{array}$ & 5,170 & 0,270 & Rejected \\
\hline $\begin{array}{l}\text { H3a There is a relationship between gender and food } \\
\text { safety }\end{array}$ & 4,364 & 0,113 & Rejected \\
\hline H3b Relationship between age and food safety & 3,115 & 0,536 & Rejected \\
\hline H3c Relationship between occupation and food safety & 7,217 & 0,125 & Rejected \\
\hline $\begin{array}{c}\text { H4a There is a relationship between gender and } \\
\text { intention to purchase }\end{array}$ & 7,328 & $<0,05$ & Accepted \\
\hline $\begin{array}{l}\mathrm{H} 4 \mathrm{~b} \text { There is a relationship between Age and intention } \\
\text { to purchase }\end{array}$ & 3,372 & 0,498 & Rejected \\
\hline $\begin{array}{l}\mathrm{H} 4 \mathrm{c} \text { There is a relationship between the profession and } \\
\text { the intention to purchase }\end{array}$ & 5,616 & 0,230 & Rejected \\
\hline
\end{tabular}

The effects of the data obtained by the analysis of the data and the revised model are given in Figure 2.

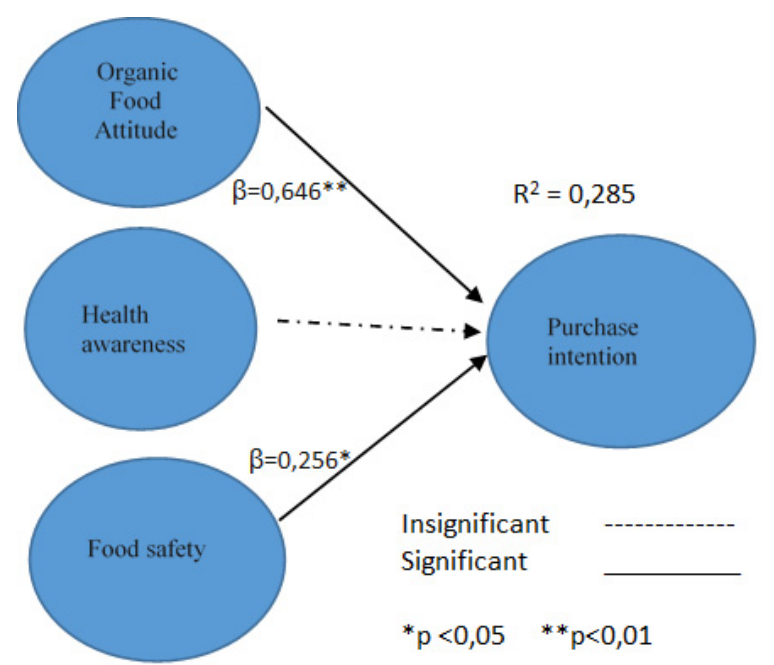

Fig 2. Total Impacts and Revised Model

\section{Conclusion}

The study revealed that the attitude towards organic foods was very effective on buying organic food. The aim of the study was to determine the importance of food safety perception. The results of the perception of attitude towards organic foods and food safety perceptions were found consistent. 
In this study, there was no effect of health awareness on the intention of buying organic food. The reason for this is that $83 \%$ of the selected sample group is under 30 years old and a significant part of it is due to the fact that it is a student group. It can be thought that the consumers in the young group are a little more distant from health awareness and prefer to have cheap and / or easily accessible food preference negatively affecting the organic food purchasing intent.

The relationship with demographic variables is related to purchasing intention for organic foods and attitudes towards organic foods. Accordingly, there is a relationship between gender and the intention to buy organic food. Likewise, it was found that there is a relationship between the profession and attitude variable for organic foods. On the other hand, the relationship between gender and food safety, health awareness and attitude variables was rejected. The relationship between age and food safety, health awareness, attitude and purchasing intention variables was rejected. Similarly, the relationship between occupation, food safety, health awareness, and intention to buy seems to be rejected. In the context of the sample of this study, it can be said that the result is not different from the literature because the presence of close age group and relatively young and professional class of this age group are more middle and lower income levels. To sum up, the research concluded that higher income groups, middle and older, married and educated consumers have more intentions to purchase organic food.

\section{References}

1. Ronald, Pamela C., and Raoul W. Adamchak. Tomorrow's table: organic farming, genetics, and the future of food. Oxford University Press, 2018.

2. Srinieng, Sansern, and Gopal Bahadur Thapa. "Consumers' Perception of Environmental and Health Benefits, and Consumption of Organic Vegetables in Bangkok." Agricultural and Food Economics 6.1 (2018): 5.

3. Carfora, V., et al. "Moderating effects of proenvironmental self-identity on pro-environmental intentions and behavior: A multi-behaviour study." Journal of Environmental Psychology53 (2017): 92-99.

4. Fishbein, Martin, and Icek Ajzen. "Attitudes towards objects as predictors of single and multiple behavioral criteria." Psychological review 81.1 (1974): 59.

5. Gould, Stephen J. "Consumer attitudes toward health and health care: A differential perspective." Journal of Consumer Affairs 22.1 (1988): 96-118.

6. Putrevu, Sanjay, and Kenneth R. Lord. "Comparative and noncomparative advertising: Attitudinal effects under cognitive and affective involvement conditions." Journal of Advertising 23.2 (1994): 77-91.

7. Roddy, Gerardine, Cathal A. Cowan, and George Hutchinson. "Consumer attitudes and behaviour to organic foods in Ireland." Journal of International Consumer Marketing 9.2 (1996): 41-63.

8. Husnain, M. I. U., M. Khan, and H. Z. Mahmood. "An assessment of public and private benefits of organic farming in Pakistan." JAPS: Journal of Animal \& Plant Sciences 27.3 (2017). 